\title{
Ervaringen van co-assistenten in de eerste twee weken van een vernieuwde klinische fase
}

\author{
J.C.G. Jacobs, S. Bolhuis, J.A. Bulte, R.S.G. Holdrinet
}

\section{Samenvatting}

Inleiding: De overgang van de eerste jaren van de medische opleiding naar de co-schappen kan voor studenten moeilijk zijn: nieuwe ervaringen en een nieuwe rol. Doel van dit onderzoek was na te gaan hoe co-assistenten halverwege het Introductie Co-schap van het vernieuwde Nijmeegse curriculum geneeskunde, deze nieuwe leersituatie ervaren.

Methode: Inhoudsanalyse van notities van co-assistenten over hun ervaringen in de eerste twee weken van het co-assistentschap. Na twee weken worden begeleidingsgesprekken gehouden waarvoor voorbereidingsformulieren zijn gë̈ntroduceerd met zes open vragen, zoals "Welke ervaring heeft $u$ het meest getroffen tot nu toe in het co-schap?" en "Hoe voelt u zich in uw functioneren als co-assistent?".

Resultaten: De helft van de co-assistenten gaf aan zich na twee weken duidelijk meer op hun plaats te voelen dan bij aanvang van het co-schap. De meeste co-assistenten vonden hun contact met patiënten goed, maar omgaan met patiënten met kanker en stervende patiënten was moeilijk. Over de samenwerking met supervisoren, verpleegkundigen en collega co-assistenten was men tevreden. Er waren veel leermogelijkheden in het Introductie Co-schap, waaronder contacten met nieuwe patiënten, het uitvoeren van vaardigheden als venapuncties en de mogelijkheid om vragen te stellen. Initiatief tonen bleek belangrijk.

Conclusies en discussie: De overgang naar de nieuwe leersituatie lijkt in het Introductie Co-schap redelijk geleidelijk te verlopen. De persoonlijke ervaringen van studenten in het eerste co-schap verdienen extra aandacht. Voor begeleiders is het belangrijk om stil te staan bij de ervaringen die studenten zelf centraal stellen, zowel in het begeleidingsgesprek als in de werkgroepbijeenkomsten van het Introductie Co-schap. (Jacobs JCG, Bolhuis S, Bulte JA, Holdrinet RSG. Ervaringen van co-assistenten in de eerste twee weken van een vernieuwde klinische fase. Tijdschrift voor Medisch Onderwijs 2004;23(4): 178-185.)

\section{Inleiding}

De overgang van de voornamelijk theoretische eerste jaren van de medische opleiding naar de co-schappen kan voor studenten problematisch zijn. ${ }^{1-3}$ Prince et al. kwalificeerden de overgang zelfs als de 'shock of practice'. ${ }^{2}$ Bij aanvang van de co-schappen worden studenten vaak overladen met nieuwe ervaringen: een hectisch medisch bedrijf, contact met soms jonge en ernstig zieke mensen, wennen aan een nieuwe rol ('the white coat' ${ }^{4}$ ) en het participeren in professionele sociali- satieprocessen. ${ }^{5-7}$ Soms ervaren co-assistenten hun theoretische kennis als onvoldoende of als slechts matig toepasbaar. ${ }^{2}$

In het vernieuwde Nijmeegse curriculum ${ }^{8}$ is veel aandacht voor zowel de klinische toepasbaarheid van kennis en vaardigheden als voor klinisch redeneren, en de onderwijsblokken hebben een duidelijk probleemgeoriënteerd karakter. Voorts is een nieuw Introductie Co-schap van vier weken ingevoerd om de student in een veilige omgeving te laten wennen aan zijn/ haar nieuwe rol als aankomend arts. Om 
te onderzoeken hoe de studenten in dit vernieuwde curriculum de overgang naar de co-assistentschappen ervaren, zijn de notities die co-assistenten maakten ter voorbereiding op het begeleidingsgesprek halverwege het co-schap geanalyseerd.

\section{Introductie Co-schap}

Het Introductie Co-schap duurt vier weken en bestaat uit een centraal deel en een afdelingsgebonden programma. Het centrale deel bestaat uit werkgroepbijeenkomsten gesitueerd buiten de kliniek. Het afdelingsgebonden deel vindt plaats op de verpleegafdelingen van zes specialismen van het UMC, die gezamenlijk de verantwoordelijkheid hebben voor dit co-schap (zie figuur 1). Het betreft de specialismen gynaecologie, heelkunde, interne geneeskunde, kindergeneeskunde, neurologie en psychiatrie. De co-assistenten worden ingedeeld op één afdeling en rouleren niet.

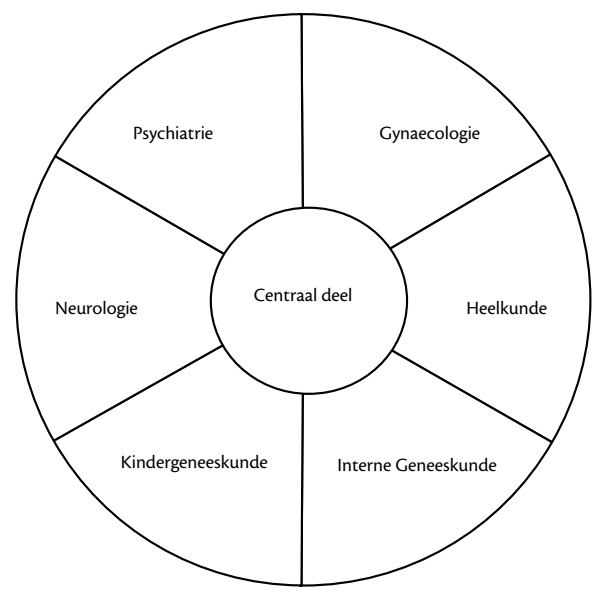

Figuur 1. Schematische weergave Introductie Coschap. In het centrale, niet-afdelingsgebonden programma van dit co-schap vinden werkgroepbijeenkomsten plaats, met aandacht voor klinisch redeneren, het uitwisselen van ervaringen en reflectie op doelstellingen, omgaan met geweld en de juridische positie van co-assistenten.
Maandelijks start er een groep van achttien co-assistenten. Voor het eerst heeft de co-assistent min of meer zelfstandig contact met patiënten. Bij zes of meer patiënten neemt de co-assistent een anamnese af en voert hij/ zij een lichamelijk onderzoek uit. De betreffende statusverslagen worden besproken met de begeleider. De co-assistent vervolgt de betreffende patiënten tijdens het Introductie Co-schap, bekijkt de uitslagen van onderzoeken en kijkt mee bij de totstandkoming van de behandelplannen. Het co-schap is erop gericht dat co-assistenten zich bewust worden dat 'leren in de praktijk' een actieve opstelling vergt.

Het Introductie Co-schap is de start van de klinische fase die naast de gebruikelijke klinische stages, drie Centrale Co-schappen omvat. Dit zijn terugkomperioden van vier weken tussen de gebruikelijke stages, met als doel het stimuleren van reflectie op ervaringen en het voorbereiden op de komende co-schappen. In alle co-schappen zijn tussentijdse begeleidingsgesprekken en afsluitende beoordelingsgesprekken ingevoerd.

\section{Het voorbereidingsformulier voor het begeleidingsgesprek}

Ook halverwege het Introductie Co-schap vindt een begeleidingsgesprek plaats waarin een co-assistent zijn/ haar ervaringen met een staflid bespreekt. Ter ondersteuning van het begeleidingsgesprek en ter bevordering van de reflectie door coassistenten is een voorbereidingsformulier ingevoerd dat bestaat uit zes open vragen (zie tabel 1). Naderhand worden de feedback van het staflid en de geformuleerde leerdoelen voor het resterende deel van het co-schap genoteerd en behoudt de student het formulier. Het is mogelijk dat co-assistenten hun antwoorden op het formulier enigszins afstemmen op 
hun begeleider omdat zij zich zo goed mogelijk willen presenteren.

Tabel 1. Voorbereidingsformulier voor begeleidingsgesprek.

1. Welke ervaring heeft $u$ het meest getroffen tot nu toe in het co-schap?

2. Hoe voelt $\mathrm{u}$ zich in uw functioneren als co-assistent op dit moment tijdens het co-schap?

3. Hoe verloopt uw omgaan met patiënten?

4. Wat gaat er goed? Wat gaat minder goed?

5. Waar heeft u moeite mee? Welke vragen, opmerkingen of problemen heeft $u$ bij de discipline (het vak) of over specifieke ziektebeelden, vaardigheden of behandelingen? Hoe verloopt het omgaan met begeleiders en andere artsen, met verpleging en met collega co-assistenten?

6. Welke mogelijkheden heeft $\mathrm{u}$ om dingen te leren en ervaring op te doen? Opmerkingen over de organisatie van het co-schap? Verdere vragen of opmerkingen?

Aan de achterzijde van het formulier worden de feedback van de begeleider en de geformuleerde, individuele leerdoelen voor het resterende deel van het co-schap genoteerd.

In de literatuur wordt een aantal studies beschreven die zich richtten op de ervaringen van beginnende co-assistenten. In portfolio's van medisch studenten in hun eerste klinische jaar ${ }^{7}$ beschreven zij een gebrek aan geloofwaardigheid tegenover patiënten en stress door het besef van de toekomstige verantwoordelijkheid voor patiënten, die meer eisen stelt aan het studiegedrag. Ook voelden zij zich buitenstaanders in het ziekenhuis. Opmerkelijk was dat de onzekerheid van de studenten in de portfolio's sterk contrasteerde met hun zelfverzekerde houding tijdens de werkgroepbijeenkomsten. ${ }^{7}$ Elders schrijven dezelfde auteurs over de emotionele impact van de eerste patiëntencontacten, de hulpeloosheid in relatie tot ernstige ziekten en overlijden, en de ervaren rolon- duidelijkheid bij lichamelijk onderzoek van leeftijdsgenoten van het andere geslacht. ${ }^{3}$ Studenten gaven ook aan zich schuldig te voelen omdat zij patiënten min of meer 'gebruikten' voor hun eigen leerproces.

In een ander onderzoek werd startende co-assistenten, evenals de artsen die bij het onderwijs aan co-assistenten betrokken waren, gevraagd naar hun angsten in de medische praktijk. ${ }^{9}$ De situaties die coassistenten noemden, hadden betrekking op de omgang met de senior medische staf en het uitvoeren van eenvoudige praktische ingrepen. De ervaren artsen bleken zich niet meer goed in de positie van co-assistenten te kunnen verplaatsen en benoemden andere situaties dan de coassistenten.

\section{Onderzoeksvragen}

1. Welke ervaringen beschrijven beginnende co-assistenten op de voorbereidingsformulieren? Komen deze ervaringen overeen met wat er in de literatuur beschreven wordt?

2. Geven co-assistenten hun ervaringen voldoende eerlijk weer om als basis te dienen voor een begeleidingsgesprek?

3. Verschaffen deze ervaringen aanwijzingen over hoe het Introductie Coschap voldoet aan de doelstellingen?

4. Welke inzichten bieden deze voorbereidingsformulieren met betrekking tot de begeleiding van beginnende coassistenten?

\section{Methode}

De voorbereidingsformulieren - in feite onderwijsinstrumenten - werden gebruikt als onderzoeksmateriaal. Aan 52 co-assistenten (12 mannen, 40 vrouwen) in drie opeenvolgende co-groepen (septembernovember 2001) werd acht weken na het Introductie Co-schap gevraagd of men 
wilde participeren in deze studie. De respons bedroeg 51 co-assistenten (98\%). De co-assistenten waren evenredig verdeeld over de zes specialismen. Omdat de 'consent'-procedure achteraf plaatsvond, mag aangenomen worden dat het design van de studie niet geleid heeft tot een vertekening van de antwoorden op de voorbereidingsformulieren. Om na te gaan of de coassistenten wellicht hun antwoorden enigszins positiever formuleerden, werd naderhand een vierde groep co-assistenten $(n=18)$ hierover bevraagd.

Er werd een inhoudsanalyse van de voorbereidingsformulieren uitgevoerd met het programma Kwalitan. ${ }^{10}$ Hierbij werd uitgegaan van thema's die uit de formulieren naar voren kwamen. Indien uitspraken van slechts twee co-assistenten relevant waren ten opzichte van bevindingen elders zijn ze opgenomen in de beschrijving van de resultaten.

\section{Resultaten}

De resultaten zullen worden gepresenteerd aan de hand van de vragen van het voorbereidingsformulier.

\section{Welke ervaring heeft $u$ het meeste getrof- fen tot nu toe in het co-schap?}

Het contact met patiënten van hun eigen leeftijd trof co-assistenten het meest $(n=16)$. Een enkeling $(n=2)$ noemde het lichamelijk onderzoek bij patiënten van hun eigen leeftijd emotioneel gezien anders dan bij andere patiënten. Verder gaf men aan de confrontatie met kanker $(n=10)$ en sterven moeilijk te vinden, met name bij een suïcidepoging $(n=4)$ of een ernstig ziek kind $(n=2)$. Gesprekken met patiënten met een oncologische aandoening en hun familie maakten grote indruk. Ook het besef dat de geneeskunde zijn beperkingen heeft, werd beschreven $(\mathrm{n}=3)$.
Sommige antwoorden waren specifiek voor een bepaald specialisme, zoals bijvoorbeeld de ervaren openheid van patiënten over intieme kwesties (gynaecologie), het bijwonen van operaties (heelkunde), het zien van een psychose (psychiatrie) en de lange wachtduur voor een overplaatsing naar een verpleeghuis (neurologie).

\section{Hoe voelt u zich in uw functioneren als co-assistent op dit moment tijdens het co-schap?}

De helft van de co-assistenten gaf aan dat zij zich na twee weken duidelijk meer op hun plaats voelden dan bij aanvang van het co-schap $(n=24)$. Soms voelden zij zich nog wat onzeker $(n=13)$. Enkele studenten noemden expliciet dat het Introductie Coschap voor hen een veilige omgeving bood. Andere opmerkingen betroffen de hiërarchie in de professie $(n=10)$, onvoldoende kennis $(n=6)$, de noodzaak van een actieve opstelling $(n=4)$ en het 'weinig kunnen' $(n=2)$. Twee co-assistenten hadden er moeite mee patiënten slechts voor hun eigen leerproces te 'gebruiken' zonder dat dit voordeel opleverde voor de patiënten.

\section{Hoe verloopt uw omgaan met patiënten? Wat gaat er goed? Wat gaat minder goed? Waar heeft u moeite mee?}

De reacties op deze vraag zijn in te delen in drie categorieën: persoonlijke karakteristieken, de nieuwe rol en technische aspecten. De meeste co-assistenten $(n=43)$ vonden hun contact met patiënten goed. Negen studenten gaven aan dat het wennen aan de nieuwe rol en het aannemen van een professionele houding moeilijker was dan men zich had voorgesteld.

Sommige co-assistenten vonden het moeilijk lange, gedetailleerde antwoorden van patiënten te onderbreken $(n=9)$. Enkele co-assistenten $(n=6)$ gaven aan het lastig te vinden wanneer patiënten hen 
vragen stelden over de diagnose of prognose. Anderen $(n=5)$ waren onzeker over hun capaciteiten in het lichamelijk onderzoek of vonden het moeilijk om contact te leggen met een ziek kind. Bij gynaecologie vond men een duidelijke taakstelling ontbreken: de patiënten waren eerder al uitgebreid onderzocht en operaties waren gepland.

\section{Welke vragen, opmerkingen of proble- men heeft $u$ bij de discipline (het vak) of over specifieke ziektebeelden, vaardigheden of behandelingen?}

Een deel van de co-assistenten $(\mathrm{n}=13)$ had geen vragen, opmerkingen of problemen. Sommigen noemden een algemeen gebrek aan kennis $(n=10)$ en vragen over medicatie $(n=6)$. Andere vragen gingen over het lichamelijk onderzoek, diagnostisch beleid, behandelplan, chirurgische terminologie, infuusbeleid, voeding en het postoperatief beleid. Ook vroeg men zich af hoe belastend het voor een patiënt met kanker zou zijn wanneer een co-assistent doorvraagt naar klachten en voorgeschiedenis. Bij neurologie vond men de confrontatie met jonge patiënten met een ernstig functieverlies moeilijk. Psychiatrie noemde men interessanter dan verwacht, hoewel psychiatrische problematiek soms moeilijk invoelbaar was. Van heelkunde vond men het prettig dat veel vaardigheden geoefend konden worden.

\section{Hoe verloopt het omgaan met begelei- ders en andere artsen, met verpleeg- kundigen en collega co-assistenten?}

De meeste co-assistenten $(\mathrm{n}=48)$ noemden hun contacten met begeleiders, verpleegkundigen en collega co-assistenten goed of plezierig. De algemene indruk die coassistenten van arts-assistenten hadden was dat zij het druk hadden, maar zich desondanks vriendelijk opstelden naar co- assistenten en patiënten. Ook stelden artsassistenten relevante vragen aan co-assistenten. Het contact met het verpleegkundig team was over het algemeen goed. Ook de omgang met collega co-assistenten was goed: onderlinge steun en het delen van ervaringen waren belangrijk. Het werken binnen een team vond men aangenaam, er werden geen obstakels ervaren, maar wel een duidelijke hiërarchie. Bij elk specialisme werd het zeer gewaardeerd wanneer een co-assistent initiatief toonde.

\section{Welke mogelijkheden heeft $u$ om dingen te leren en ervaring op te doen? Opmer- kingen over de organisatie van het co- schap? Verdere vragen of opmerkingen?}

Ruim een derde $(n=19)$ van de co-assistenten zei dat er veel leermogelijkheden waren in het Introductie Co-schap. Belangrijk waren de contacten met nieuwe patiënten $(\mathrm{n}=11)$ waar men leerde anamnese en lichamelijk onderzoek uit te voeren bij een (echte) patiënt. Verder vonden co-assistenten $(n=10)$ het erg belangrijk om praktische vaardigheden te oefenen, zoals venapuncties en het inbrengen van infusen. Co-assistenten benadrukten dat wanneer zij vragen hadden, zij deze meteen aan arts-assistenten konden stellen. Andere leermomenten in het Introductie Co-schap die genoemd werden, waren de patiëntenbesprekingen $(n=6)$, onderwijspraatjes door stafleden $(n=4)$, de werkgroepbijeenkomsten over klinisch redeneren, het samenvatten van patiëntenstatussen, extra contact met patiënten en het observeren van een arts-assistent in diens dagelijkse activiteiten. De co-assistenten vonden dat psychiatrie minder leermomenten bood dan de andere vijf specialismen, enerzijds vanwege het minder frequent uitvoeren van lichamelijk onderzoek, anderzijds omdat co-assistenten 
geen psychiatrische anamnese afnamen, zodat de anamnese beperkt bleef tot somatische aspecten. Over het geheel genomen waren alle co-assistenten tevreden met de organisatie van het Introductie Coschap.

Naar aanleiding van het vermoeden dat de antwoorden op de zes vragen van het voorbereidingsformulier enigszins aangepast werden aan de gesprekspartner, werd in tweede instantie aan een vierde groep co-assistenten gevraagd hoe de voorbereidingsformulieren ingevuld werden. Zij bevestigden ons vermoeden dat zij soms probeerden zich zo goed mogelijk te presenteren en niet altijd volledig waren. Zo noteerden co-assistenten bijvoorbeeld dat men 'veel kon doen' als het betreffende staflid van mening was dat het co-schap op zijn/ haar afdeling voldoende leerzaam was mits men zich voldoende actief opstelde. Desondanks vonden co-assistenten het voorbereidingsformulier voor het tussentijds begeleidingsgesprek een zinvol instrument dat stimuleerde tot reflectie en het begeleidingsgesprek ondersteunde.

\section{Conclusies en Discussie}

\section{Relatie tussen bevindingen en literatuur}

De ervaringen die co-assistenten als 'meest indrukwekkend' beschreven op het voorbereidingsformulier voor het begeleidingsgesprek dat plaatsvond na twee weken Introductie Co-schap, betroffen contacten met patiënten met kanker en stervende patiënten. Er waren veel mogelijkheden om te leren in het Introductie Co-schap. Belangrijk waren de contacten met nieuw opgenomen patiënten en het uitvoeren van vaardigheden als venapuncties. Sommige co-assistenten vonden dat psychiatrie minder leermomenten bood dan de andere specialismen.
Er werd door de 51 co-assistenten nauwelijks negatieve kritiek geformuleerd op de supervisie en de leeromstandigheden. De meest voor de hand liggende verklaring is dat men nauwelijks kritiek heeft, hoewel misschien ook onzekerheid om kritiek te bespreken of een mogelijk negatief effect op de beoordeling een rol kunnen spelen.

Slechts door sommige co-assistenten (namelijk 10 van 51) werd een kennistekort zoals beschreven door Prince et al. ${ }^{12}$ vermeld op de voorbereidingsformulieren. Ook de verandering in klinisch denken, namelijk van symptomen naar diagnose (door studenten wel gekarakteriseerd als 'het andersom denken') werd niet genoemd. Een ander verschil met de studie van Prince et al. ${ }^{12}$ was dat de co-assistenten onzekerheid weinig benoemden. Het is niet uitgesloten dat dit samenhangt met de zelfpresentatie van co-assistenten ten aanzien van stafleden, maar wij verwachten dat ook het nieuwe curriculum en de opzet van het Introductie Co-schap hierin een rol spelen.

De bevindingen van de portfolio-analyse door Pitkälä en Mantyranta ${ }^{3}$ ziet men deels terug in de voorbereidingsformulieren: met name de emotionele impact van de eerste patiëntencontacten en de hulpeloosheid in relatie tot ernstige ziekten en overlijden. Stress door het besef van de toekomstige verantwoordelijkheid voor patiënten wordt op de voorbereidingsformulieren niet vermeld, wellicht omdat dit in de eerste twee weken van dit co-schap nog weinig speelt.

Een belangrijke constatering is de door Pitkälä en Martyranta waargenomen discrepantie tussen de onzekerheid die studenten in de portfolio's aangeven en de zelfverzekerde houding van de studenten tijdens de werkgroepbijeenkomsten. ${ }^{7}$ Dit ondersteunt het belang van voldoende 
aandacht voor de voorbereidingsformulieren bij het begeleidingsgesprek.

Angst voor het contact met de senior medische staf en voor het uitvoeren van eenvoudige praktische ingrepen 8 werd door de co-assistenten in het Introductie Co-schap nauwelijks meer genoemd. Mogelijke verklaringen hiervoor zijn dat de hedendaagse, vaak als 'mondig' gekarakteriseerde co-assistenten beter voorbereid zijn op de klinische fase, dat het Introductie Co-schap een veilige leeromgeving biedt en dat het onderwijs stimuleert tot zelfstandigheid en initiatief en niet zozeer gebaseerd is op autoritaire verhoudingen.

\section{Geven co-assistenten hun ervaringen voldoende eerlijk weer om als basis te dienen voor een begeleidingsgesprek?}

Hoewel een vierde groep co-assistenten aangaf dat de antwoorden op het formulier enigszins aanpast werden aan het staflid met wie het begeleidingsgesprek gevoerd werd, wijst de diversiteit van de geanalyseerde antwoorden erop dat de beschreven ervaringen zeker als basis kunnen dienen voor een goed begeleidingsgesprek.

\section{Verschaffen deze ervaringen aanwijzin- gen over hoe het Introductie Co-schap voldoet aan de doelstellingen?}

De resultaten wijzen erop dat het Introductie Co-schap de studenten de gelegenheid biedt op een geleidelijke en veilige wijze te wennen aan hun nieuwe rol als dokter. Belangrijk is dat taken en verantwoordelijkheden duidelijk zijn, zowel voor henzelf als voor begeleiders en verpleegkundigen. Ook het reflecteren op ervaringen en het groepscontact in de werkgroepbijeenkomsten zijn waardevol.

\section{Welke inzichten bieden de voorberei- dingsformulieren met betrekking tot de begeleiding van beginnende co-assis- tenten?}

De opzet van de voorbereidingsformulieren met open vragen stimuleert studenten tot het nadenken over hun eigen ervaringen. Voor begeleiders biedt het aangrijpingspunten om stil te staan bij de ervaringen die studenten zelf centraal stellen. Verder bieden de resultaten van de beschreven inhoudsanalyse aangrijpingspunten om in het onderwijs en de begeleiding gericht te anticiperen op als lastig ervaren momenten. Zo is het aan te bevelen om tijdens het Introductie Co-schap tijdens de werkgroepbijeenkomsten, maar ook tijdens het leren op de afdelingen meer aandacht te besteden aan het omgaan met ernstig zieke leeftijdsgenoten of met stervende patiënten, zoals ook elders wordt bepleit. ${ }^{11}$ Ook zou men kunnen overwegen om mentorgroepen voor startende co-assistenten te introduceren met expliciet aandacht voor onzekerheidsgevoelens en kritische vragen.

In dit onderzoek is authentiek materiaal geanalyseerd. Het voorbereidingsformulier bevat doelbewust open vragen om studenten te stimuleren tot reflectie, hoewel onderzoekstechnisch een formulier met gesloten antwoordcategorieën misschien voordelen zou hebben. In een vervolgonderzoek kan middels diepte-interviews of focusgroepgesprekken met beginnende co-assistenten verder ingegaan worden op de overgang naar de klinische fase.

\section{Concluderend}

De persoonlijke ervaringen van studenten in het eerste co-assistentschap verdienen extra aandacht en het beschreven voorbereidingsformulier kan hierin een zinvolle 
functie hebben. Voor begeleiders is het belangrijk om stil te staan bij de ervaringen die studenten zelf centraal stellen, zowel in het begeleidingsgesprek van het Introductie Co-schap en de begeleiding in de kliniek, als in de werkgroepbijeenkomsten.

\section{Literatuur}

1. Becker HS, Hughes EC, Geer B, Strauss AL. Boys in white: student culture in medical school. Toronto: University of Toronto Press; 1961.

2. Prince KJAH, Wiel MWJ van de, Scherpbier AJJA, Vleuten CPM van der, Boshuizen HPA. A qualitative analysis of the transition from theory to practice in undergraduate training in a PBL-medical school. Adv Health Sci Educ 2000;5:105-16.

3. Ter perse: Pitkälä KH, Mantyranta T. Feelings related to first patient experiences in medical school. A qualitative study on students' personal portfolios. Patient Education and Counseling.

4. Russell PC. The white coat ceremony: turning trust into entitlement. Teach Learn Med 2002;14(1): 56-9.

5. Eraut M. Developing professional knowledge and competence. London/ Philadelphia: Falmer Press; 1994.

6. Winants Y. Co-assistentschappen als inwijding in de medische beroepscultuur [dissertation]. Maastricht: Universiteit Maastricht; 1999.

7. Pitkälä KH, Mantyranta T. Professional socialization revised: medical students' own conceptions related to adoption of the future physician's role a qualitative study. Med Teach 2003;25(2):155-60.
8. Holdrinet RSG, Bulte JA. Realisering van een vernieuwd Nijmeegs curriculum Geneeskunde. Nijmegen: Faculteit der Medische Wetenschappen, Katholieke Universiteit Nijmegen; 2002.

9. Moss F, McManus I. The anxieties of new clinical students. Med Educ 1992;26:17-20.

10. Peters V. Kwalitan. http://www.kwalitan.net, geraadpleegd in april 2004.

11. Wear D. "Face-to-face with it": medical students' narratives about their end-of-life education. Acad Med 2002;77(4):271-7.

De auteurs:

Mw. drs. J.C.G. Jacobs is arts en onderwijskundige.

$M w . d r . S$. Bolhuis is onderwijskundige en senior-onderzoeker.

Drs. J.A. Bulte is onderwijskundige en senior beleidsmedewerker.

Prof. dr. R.S.G. Holdrinet is internist-hematoloog en hoogleraar Medisch Onderwijs.

Allen zijn verbonden aan de afdeling Ontwikkeling en Onderzoek van Medisch Onderwijs van het Onderwijsinstituut UMC St Radboud, Nijmegen.

Correspondentieadres:

Mw. drs. J.C.G. Jacobs, UMC St Radboud, Onderwijsinstituut, Afd. Ontwikkeling en Onderzoek van Medisch Onderwijs, Interne postcode 224 KTC, Postbus 9101, 6500 HB Nijmegen, tel: 024-3619051, fax: 024-3560433, a.jacobs@educ.umcn.nl.

\section{Summary}

Introduction: The transition from the preclinical years of the undergraduate medical curriculum to clinical training in the clerkships can be difficult, because students have to adjust to new experiences and a new role. We wanted to explore students' perceptions of their new learning environment half way the Introductory Clerkship of the innovated undergraduate medical curriculum of Nijmegen medical school.

Method: We used content analysis to examine students' notes on their experiences in the first two weeks of clerkship. After these two weeks, there is a formative appraisal. For this appraisal a so-called 'preparation sheet' is used with six open questions asking students among other things to indicate their most salient experiences and how they feel about their functioning.

Results: Half of the students indicated that they had got used to the new situation after two weeks. Most students indicated that contacts with patients were good, although being confronted with cancer patients and dying patients was difficult. The students expressed satisfaction about their relationships with supervisors, nurses and fellow students. The Introductory Clerkship offered many learning opportunities, such as contacts with newly admitted patients, opportunities to practise skills like venepuncture and ask questions. The students mentioned that it was important to show initiative. Conclusions and discussion: The Introductory Clerkship appears to provide a fairly smooth transition to the new learning environment. It appears to be important to focus on students' personal experiences. Mentors should be especially attentive to students' personal experiences both in the appraisal interview and in the work group sessions in the Introductory Clerkship. (Jacobs JCG, Bolhuis S, Bulte JA, Holdrinet RSG. Students' experiences in the first two weeks of clerkship in an innovated undergraduate medical curriculum. Dutch Journal of Medical Education 2004;23(4): 178-185.) 